is caused by drawing too fine a distinction between these terms.

The fundamental antibacterial action of penicillin and sulphonamides is inhibition of cell multiplication. Sulphonamides inhibit the growth of almost every variety of cell besides bacteria, although in widely varying concentration; there is as yet little evidence that penicillin will have such a general effect, but Cornman has reported survival of normal cells in penicillin solutions lethal to malignant cells ${ }^{9}$. Sulphonamide action is usually biphasic ; our observations suggest that this may be true of penicillin. Primary bacterial proliferation preceding bacteriostasis, as occurs with sulphonamides, has recently been noted with penicillin and Leptospira icterohomorrhagioe ${ }^{10}$. (As mentioned previously, this may well be another aspect of the biphasic phenomenon.) Penicillin growth-inhibition, in conformity with that of sulphonamides, appears to obey the law of mass action, in that $(a)$ the inhibition is reversible, by removing the bacteria from contact with penicillin or destroying the penicillin with penicillinase, and (b) the inhibition is directly related to the penicillin concentration $^{3}$. Both penicillin ${ }^{6,8}$ and sulphonamide activity are directly related to the temperature. In the presence of a constant amount of sulphonamide, antibacterial activity is inversely related to the number of organisms present; this is a phenomenon which awaits satisfactory explanation; and the explanation is also required in respect of penicillin 6 . A feature of sulphonamide activity is that it varies from one bacterial species to another, from strain to strain, and even perhaps from organism to organism. Penicillin exemplifies this selectivity par excellence. Antibacterial effect is greatly influenced by the sulphonamide chemical structure, and scientific progress with penicillin must be seriously impeded until its structure is made known. By analogy, however, there is every reason to expect that substances chemically related to penicillin will have different bacterial 'spectra'. Chemical information is also lacking for a comparison of the effect of $p H$ changes on penicillin action; at present this factor appears more important to sulphonamide action. Organisms can be trained to resist either penicillin or sulphonamides to a surprising degree, and with almost equal ease. Penicillin shares with sulphonamides synergism of antibacterial effect by antibodies and cellular defence mechanisms.

The commonly accepted theory of sulphonamide action, that of Woods and Fildes, casts $p$-aminobenzoic acid in an essential role ${ }^{11}$. Since this substance plays no similar part in penicillin action, some fundamental difference in mode of action might be presumed. But Henry's conclusions throw considerable doubt on the Woods-Fildes explanation, and reconcile this apparent anomaly in sulphonamidepenicillin similarity ${ }^{7}$. There appears to be general agreement that sulphonamide bacteriostasis is achieved by direct inhibition of one or more enzymes. The profound biological activity shown by penicillin in trace concentrations would appear to be eminently explicable in terms of enzymic phenomena. It is not our purpose, however, to speculate on the mode of action of penicillin; but to suggest, on the basis of empirical observations available now, that it is not likely to be fundamentally unique. The differences that do exist between sulphonamides and penicillin, and which place the latter in its preeminent therapeutic position, appear to be differences of degree so far as mode of action is concerned.
Much of the technical work on which our observations are based was performed by laboratory assistants in the Royal Navy, to whom we are indebted. The crystalline penicillin was generously given by I.C.(P.), Ltd.

Addendum. Additional information has become available since this communication was written. It is now clear that at least three chemically different varieties of penicillin have already been identified and that their relative efficiencies for various bacteria are probably different ${ }^{12}$. The effect of $p H$ on penicillin activity ${ }^{13}$ is, in fact, in striking conformity with what has been reported for sulphonamides. The direct relationship of temperature to penicillin activity has been amplified ${ }^{13,14}$. Todd ${ }^{15}$ has demonstrated the frequency with which primary multiplication occurs in cultures subjected to the influence of penicillin, and noted that Fleming originally reported this phenomenon in 1929 .

\footnotetext{
${ }^{1}$ Woolley, D. W., and White, A. G. C., J. Expt. Med., 78, 489 (1943). 2 Finklestone-Sayliss et al., Lancet, ii, 792 (1937). Green, H. N., Brit. J. Expt. Path., 21, 38 (1940). Green, H. N., and Bielschowrky, F., Brit. J. Expt. Path., 23, 1 (1942). Lamanna, C., Science, 95, 304 (1942). Lamanna, C., and Shapiro, I. M., J. Bact., 45, 385 (1943). Colebrook et al., Lancet, ii, 1323 (1936). McIntosh, J., and Whitby, E. H., Lancet (i), 431 (1939)

${ }^{3}$ Foster, J. W., J. Biol. Chem., 144, 285 (1942). Foster, J. W., and Wilkers, B. L., J. Bact., 48, 377 (1943). Foster, J. W., and Woodruff, H. B., J. Bact., 46, 187 (1943). Joslyn, D. A., Science, 99, 21 (1944). Lee et al., J. Biol. Chem., 152, 485 (1944). MeMahan, J. R., J. Biol. Chem., 153, 249 (1944).

- Gardner, A. D., Nature, 146, 837 (1940).

- Miller, C. P., and Foster, A. Z., Proc. Soc. Expt. Biol. N.Y., 56 205 (1944). Hobby, G. L., and Dawson, M. H., Proc. Soc. Expt. Biol. N.Y., 181 (1944).

'Bigger, J. W., Lancet, ii, 497 (1944).

${ }^{7}$ Henry, R. J., Bact. Rev., 7, 175 (1943)

- Garrod, L. P., Lancet, ii, 673 (1944).

- Cornman, I., Science, 99, 247 (1944).

${ }^{10}$ Alston, J. M., and Broom, J. C., Brit. Med. J., 2, 718 (1944).

11 Woods, D. D., and Fildes, P., Chem. and Ind., 59, 133 (1940).

12. See Nature, 154, 725 (1944).

${ }^{13}$ Garrod, Brit. Med. J., i, 107 (1945).

${ }^{14}$ Eagle and Musselman, J. Exp. Med., 80, 493 (1944).

${ }^{15}$ Lancet, i, 74 (1945).
}

\section{CONFERENCE ON AUDIO-VISUAL EDUCATION}

ADIO-VISUAL education and the part it must play in the schools of Hertfordshire were discussed at a whole-day conference held at Welwyn St. Măry's C.E. School on February 2.

Opening the Conference, Mr. A. R. Chorlton, deputy education officer for the county, who has done much to foster an interest in this aspect of education, commented upon the suitable atmosphere for the subject under discussion created by a set of artist's originals for a series of coloured lithographic posters dealing with the Industrial Revolution, brought for the occasion by Lieut.-Commdr. Rawnsley, of Common Ground, Ltd., and the various optical instruments and demonstration material provided by Metalair, Dufay Chromex, and a Hertfordshire school which has been specializing in audio-visual education. The Conference, he said, was the outcome of work done during the past eighteen months by the Watford and District AudioVisual Education Association and the North Herts Visual Aids Committee. Its object was to enable members of both Committees to meet and discuss a plan of action for the ensuing year.

In the absence of Mr. G. Patrick Meredith, lecturer in visual education, University College, Exeter, who 
was to have addressed the meeting, Commander Rawnsley opened the discussion on visual material and media by outlining the objects of experiments he had conducted in this field in order to provide suitable material in the form of background posters, classroom exhibitions, film-strips and films. $\mathrm{He}$ stressed the need for integrating means and material in order to produce a living situation, and argued that only thus can a child be truly educated to become a useful member of the community. To do this, teachers will have to become attuned to the visual education approach. The value of Commander Rawnsley's contribution was emphasized by the excellent teaching quality of the film-strip and film on coal, edited under the guidance of J. Fairgrieve, which complemented the exhibition.

The afternoon session was opened by Mr. A. Arkinstall, headmaster of Callow Land Boys' School, Watford. His subject was "Essentials for a Successful Audio-Visual Aids Programme". Commencing with the child - for that, he felt, is where we should start if we are to have ultimate success with any project which concerns the child-he outlined the educational pattern which must be completed if his audio-visual needs are to be met. A better understanding of the dull and backward child's point of view and environment, coupled with an education which has a good audio-visual content, would do much to reduce juvenile delinquency. In the immediate future, we should collect as much information as possible to help to put audio-visual education on a sound psychological basis. The teacher has great opportunities in this connexion. Experiments should be conducted on research lines organized by committees of local associations, and the findings passed on to the university research departments. He envisaged the time when each county would have a central clearing. house in contact on one hand with the B.B.C., Federation of British Industries, museums, Ministry of Education, local education authorities, authors (for copyright permits), university research centres, and producers of audio-visual means and material; and on the other with audio-visual associations, head teachers, training colleges, adult education centres and youth movement leaders.

At the present time schools are ill-equipped for audio-yisual education; apparatus such as wireless receivers, film-strip and film projectors, gramophones and records, together with plenty of good pictures in good sequences, all approved by teachers for quality in a teaching situation, are needed for use in rooms suitably equipped for such instructional means. Despite present shortcomings, the best use must be made of such material and means as are available in order to show by the results of one or two pieces of research work that this is a worthwhile project upon which money would be well spent.

This suggestion was followed by Mr. H. Goldsmith, one of the Ministry of Education inspectors, who gave an account of the conditions of loan to the county of a number of American strip-film projectors, each accompanied by fifty strips dealing with various aspects of life in America. He hoped that part of the research proposed would be in connexion with the evaluation of this material.

A particular feature of the Conference was the practical nature of the suggestions put forward by those contributing to the discussions in both sessions, but perhaps this was to be expected when their interest in the apparatus and material which surrounded them on all sides is considered.

\section{MANGROVES IN THE NEW WORLD}

$\mathrm{M}$

ANGROVES have been of interest to botanists ever since the first details were given by morphologists in the eighteenth century, not only to specialists in ecology on account of their somewhat peculiar distribution as shore-line vegetation, but also to the general botanist in view of the unusual morphological and physiological features which they display. It is therefore satisfactory that it has been found possible to give a very full account of the main features of these plants as observed by the 1939 Cambridge Expedition to Jamaica ${ }^{1}$. Those of us who have attempted field experiments even a short distance from the laboratory will realize full well the difficulty in assessing requirements beforehand, and it can well be understood that the performance of the Expedition falls short of its members' expectations on this account and in view of the scanty data already in the literature on which they had to rely for guidance. Nevertheless, in spite of these unavoidable difficulties and notwithstanding the cessation of activity due to the outbreak of war, Dr. Chapman presents a most impressive series of three articles ranging over a wide field of endeavour. It is stimulating to find here a clear grasp of the problems involved in attempting to relate morphological character to physiological function, with repeated emphasis on the problems yet to be solved. Work of this kind can clearly not be final, and probably the most useful feature of the Expedition, as it is reflected in these papers, lies in the guidance it gives for more detailed investigation which may become possible in the future.

The first paper surveys the botanical processes involved in the maintenance and development of the shore-line in Jamaica, and discusses the distribution and ecological significance of the range of mangroves and associated plants found on the island. In the second and third, Dr. Chapman concentrates on one particular species (Avicennia nitida Jacq.) from the point of view of its relation to its environment, its morphology, and the physiological peculiarities associated with pneumatophores.

It comes somewhat as a surprise to the uninitiated to realize the comparatively wide tolerance of mangroves to soil conditions. Here we have soils ranging from sand to mud well populated, with salinity of soil water ranging over wide limits even up to fresh water in isolated cases. It is impossible in a short space to consider the vast amount of information presented in any detail ; but it may be said in general that the drift in dune development resembles in broad outline that found in the British Isles and that the mangroves of the New World as found in Jamaica come under the "wide salt tolerance" class into which Schimper put some of the Old World species. Details of species and probable origin are given, and the brief discussion of the migration of seeds and seedlings along ocean currents, and the effects of fresh water at river estuaries, surely forms one of the most fascinating stories in all nature study.

In the second paper an attempt is made to elucidate the edaphic factors important in the growth of this mangrove, which shows optimum growth in soils with more than 0.5 per cent sodium chloride where the water content either does not fall below a certain minimum or is replenished periodically by flooding. Oxygen content is not thought to play any important part in zonation, partly because the root system has 